Article

\title{
Experimental Evaluation of a New Approach for a Two-Stage Hydrothermal Biomass Liquefaction Process
}

\author{
Marco Klemm ${ }^{1}{ }^{*}$, Michael Kröger ${ }^{1}$, Kati Görsch ${ }^{1}$, Rüdiger Lange ${ }^{2}$, Gerd Hilpmann ${ }^{2}$, \\ Farzad Lali ${ }^{2}$, Stefan Haase ${ }^{2}$, Michael Krusche ${ }^{3}$, Frank Ullrich ${ }^{3}$, Zihao Chen ${ }^{4}$, Nicole Wilde ${ }^{4}$, \\ Majd Al-Naji ${ }^{4}$ and Roger Gläser ${ }^{4}$ (1) \\ 1 DBFZ Deutsches Biomasseforschungszentrum gemeinnützige GmbH, 04347 Leipzig, Germany; \\ michael.kroeger@dbfz.de (M.K.); kati.goersch@dbfz.de (K.G.) \\ 2 Faculty of Mechanical Science and Engineering, Chair of Chemical Reaction Engineering and Process Plants, \\ Technische Universität Dresden, 01069 Dresden, Germany; ruediger.lange@tu-dresden.de (R.L.); \\ gerd.hilpmann@tu-dresden.de (G.H.); cvt@mailbox.tu-dresden.de (F.L.); stefan.haase@tu-dresden.de (S.H.) \\ 3 Advanced Machinery \& Technology Chemnitz GmbH, 09125 Chemnitz, Germany; \\ michael.krusche@amtech-htt.de (M.K.); frank.ullrich@amtech-htt.de (F.U.) \\ 4 Faculty of Chemistry and Mineralogy, Institute of Chemical Technology, Universität Leipzig, 04103 Leipzig, \\ Germany; katrin.kunze@uni-leipzig.de (Z.C.); sek.glaeser@uni-leipzig.de (N.W.); \\ info@mpikg.mpg.de (M.A.-N.); roger.glaeser@uni-leipzig.de (R.G.) \\ * Correspondence: marco.klemm@dbfz.de; Tel.: +49-(0)341-2434-537; Fax: +49-(0)341-2434-133
}

Received: 12 April 2020; Accepted: 6 July 2020; Published: 17 July 2020

\begin{abstract}
A new approach for biomass liquefaction was developed and evaluated in a joint research project. Focus of the project, called $\mathrm{FEBio@} \mathrm{H}_{2} \mathrm{O}$, lies on a two-step hydrothermal conversion. Within step 1 , the input biomass is converted employing a hydrothermal degradation without added catalyst or by homogeneous catalysis. Within step 2, the hydrogen accepting products of step 1 , e.g., levulinic acid (LA) are upgraded by a heterogeneously catalyzed hydrogenation with hydrogen donor substances, e.g., formic acid (FA). As a result, components with an even lower oxygen content in comparison to step 1 products are formed; as an example, $\gamma$-valerolactone (GVL) can be named. Therefore, the products are more stable and contained less oxygen as requested for a possible application as liquid fuel. As a hydrothermal process, $\mathrm{FEBio@} \mathrm{H}_{2} \mathrm{O}$ is especially suitable for highly water-containing feedstock. The evaluation involves hydrothermal conversion tests with model substances, degradation of real biomasses, transfer hydrogenation or hydrogenation with hydrogen donor of model substances and real products of step 1, catalyst selection and further development, investigation of the influence of reactor design, the experimental test of the whole process chain, and process assessment.
\end{abstract}

Keywords: liquefaction; hydrothermal process; transfer hydrogenation; heterogeneously catalyzed reaction; hydrogen donor; wet biomass

\section{Background of the Work}

Because of its carbon content, biomass is a potential source for renewable liquid fuels and organic chemicals with a lower carbon footprint compared to fossil products. Usually, biomass consisting of cellulose, hemicellulose, and lignin is rich in oxygen [1]. Due to storage, distribution, and application reasons, the oxygen content for liquid fuels such as gasoline or diesel fuel is restricted, e.g., by fuel specifications. Substances containing oxygen in the molecule structure such as $\gamma$-valerolactone (GVL) and valeric esters $[2,3]$ are discussed as alternative liquid fuels with preferable application behavior, 
e.g., reduced soot generation. The oxygen content of these substances is much lower than of usual biomass $(\mathrm{C} / \mathrm{O}$ ratio for $\mathrm{GVL}=2.5$; for cellulose $\approx 1)$. Common processes, such as flash pyrolysis or one-step hydrothermal liquefaction are not able to produce liquid fuels that fulfill the specifications of standard fuels, especially concerning oxygen content [4,5]. A common way of upgrading fuel intermediates with high oxygen content, is hydrogenation. Because of the oxygen content, a treatment of biogenic intermediates by hydrogenation consumes a lot of hydrogen. The oxygen content of the intermediates is within a wide range, for flash pyrolysis from $35-40 \% w / w$ and for hydrothermal liquefaction from $8-22 \% w / w$ [6]. For example, $20 \% w / w$ oxygen represents a need of hydrogen for deoxygenation and saturation in the range of $0.25-0.56 \mathrm{~m}^{3} \mathrm{~kg}^{-1}$ intermediate. This is a key factor that makes high quality biofuel provision via hydrogenation with gaseous hydrogen expensive.

An important part of available biomass potentials are substances with high moisture content. Because the water has to be removed before, normally by an energy intensive drying process, processes needing dry feedstock are very energy-inefficient with these streams. Therefore, processes with water as reaction medium are preferable.

The scope of the research work was to investigate a new approach for the production of an upgraded liquid fuel with low oxygen content, with water as reaction medium, and without consumption of gaseous hydrogen. The approach for reaching this scope within this work is a combination of hydrothermal biomass decomposition and product upgrading in aqueous phase involving hydrogenation with hydrogen donor substances (in-situ hydrogenation).

For the hydrogenation, hydrodeoxygenation, and saturation of single substances without the application of gaseous hydrogen, hydrogenation with hydrogen donor substances is a common process $[7,8]$. In-situ hydrogenation can be a transfer hydrogenation with direct transfer of hydrogen from donor to acceptor or a hydrogenation with an immediate consumption of internal produced molecular hydrogen. In addition to the advantage of no need for external hydrogen, in-situ hydrogenation offers many other advantages such as no equipment for gaseous hydrogen provision and handling, smaller reactors, no reaction limitation because of mass transfer between gaseous and liquid phases and thereby milder reaction conditions (especially lower pressure) $[9,10]$.

Watanabe [11] describes the production of an oil with a low oxygen content out of biomass and formic acid (FA) in the presence of alkali carbonate using cobalt catalysts. Zhou [12] explains that hydrogen transfer is a possible way to generate oxygen poor products. Hyde [9] uses hydrogen, in-situ produced out of FA, for the hydrogenation of unsaturated carbohydrates, but under supercritical conditions. Gilkey [13] gives an overview on the in-situ hydrogenation of several pure substances with FA at different catalysts.

For the transfer hydrogenation of levulinic acid (LA) with FA to GVL, some results are available. Deng [14] mentioned that a GVL yield of $96 \%$ is possible while utilizing Ru catalysts. Following Braden [15], an $\mathrm{RuRe} / \mathrm{C}$ catalyst is more active in the presence of sulphuric acid than a $\mathrm{Ru} / \mathrm{C}$ catalyst. Jing [16] reaches $81 \%$ GVL yield with $\mathrm{Ru} / \mathrm{C}$ catalyst, at $160^{\circ} \mathrm{C}$, and $180 \mathrm{~min}$ in presence of trietylamine. Metzker [17] reaches $92 \%$ GVL yield after $15 \mathrm{~h}$ at $180^{\circ} \mathrm{C}$ with a catalyst produced from carbonyliron.

Also, the in-situ hydrogenation of vanillin (V) to 2-methoxy-4-methylphenol (MMP) with FA was already explained. Singh [18] found a yield of $99 \%$ at $130{ }^{\circ} \mathrm{C}$ and $6 \mathrm{~h}$ in water applying a $\mathrm{Pd} 50 \mathrm{Ag} 50 / \mathrm{Fe}_{3} \mathrm{O}_{4} / \mathrm{NrGO}$ catalyst.

Pileides [19] explains that poor stability of solid catalysts under hydrothermal conditions is a major challenge of these approaches. A detailed investigation of catalyst stability was not described.

However, the addition of a hydrogen donor from an external source may not be an economic alternative to hydrogen addition. An inexpensive conversion process can be realized if it succeeds to use components from biomass as hydrogen donor for the hydrogenation of other parts in an integrated process.

A decomposition of biomass in hot compressed water, called hydrothermal decomposition, leads to a conversion of biomass macromolecules, like polysaccharides and lignin, mainly into smaller compounds. Typical products of the decomposition of carbohydrates are monomeric sugars, furan 
derivatives and carboxylic acids such as LA and FA [20-26]. With lignin as raw material, mainly aromatic compounds such as phenols are formed [27]. Some of the conversion products, especially FA, are hydrogen donor substances, applicable in in-situ hydrogenation as described above. Because of the presence of solid particles in the hydrothermal process, the possibilities for applying heterogeneous catalysts are very limited. Homogeneous catalysts, especially catalysts affecting the $\mathrm{pH}$, which are known to promote hydrothermal decomposition, have been tested.

The products of step 1 include both, typical hydrogen donors such as FA and substances that can form liquid fuel components by reaction with hydrogen such as phenols, unsaturated hydrocarbons, and LA. Based on this the new approach is a two-step process with hydrothermal decomposition as step 1 forming hydrogen donors and acceptors. In step 2, the aim is to use the formed hydrogen donors for the hydrogenation of the products of the hydrothermal decomposition step that are easy to hydrogenate to form fuel components. That is why no external reactants such as added hydrogen should be needed. The concept in principle is shown in Figure 1.

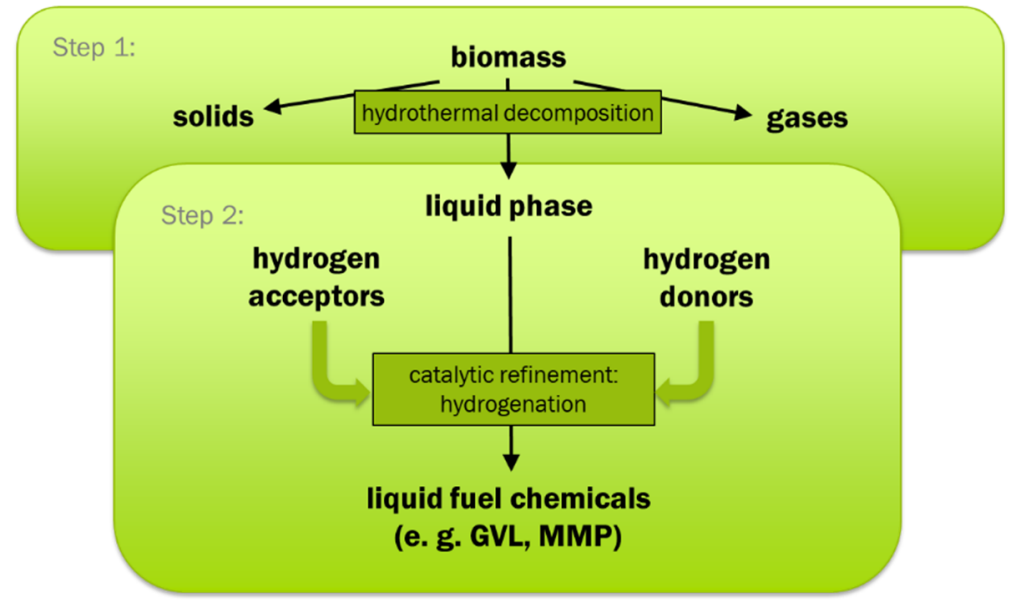

Figure 1. Schematic diagram of the approach.

Hyde [9] emphasizes the opportunities of the integration of the steps of hydrothermal biomass conversion. Within the literature, some multistage approaches for hydrothermal fuels production from biomass are described [28-31].

The approach described in this paper differs in main points from the state of the art explained briefly:

- Intermediate production of hydrogen is not the main target, this is accepted but the direct hydrogen transfer is aimed because of the above-mentioned advantages;

- The whole biomass is applied, without a lignin-carbohydrate separation, the upgrading of products of lignin degradation is investigated as well, which implies the use of the lignin part as chemical feedstock;

- Instead of supercritical water as in the process described by Hyde [13] and others, subcritical water is used, which implies milder reaction conditions combined with the possibility for a reduction of material strain;

- There is no hydrogenation of sugars to polyols as initial step planned. This implies a decrease of the $\mathrm{O} / \mathrm{C}$ ratio without hydrogen consumption during hydrothermal decomposition.

The present article mainly focuses on the introduction as well as the proof of this multi-stage concept for biomass conversion and aims to give a whole overview of the possible process chain. Details of some experimental investigation of partial steps are also published in previous publications.

For proof of concept, the following issues were investigated:

- Hydrothermal decomposition of model substances and real biomass (step 1) with the aim to 
o Maximize the yield of desired products, e.g., organic acids, phenols and unsaturated hydrocarbons which can be converted via hydrogenation with hydrogen donor substances in step 2; and

o Minimize solid by-products, e.g., insoluble humins;

- $\quad$ Selection of catalyst supports which are stable under hydrothermal conditions, represented by low decrease of the Brunauer-Emmett-Teller (BET) surface in hydrothermal experiments;

- Test of selected catalysts with model mixtures representing the products of step 1;

- Design of a laboratory plant as model for the whole process, considering the two steps of the planned process;

- $\quad$ Test of the whole process chain in laboratory scale.

\section{Materials and Methods}

In this section, the approach concerning realization of the experiments is described. Because of the different equipment, the subsections in this part of the paper refer exactly to the subsections in the results part.

\subsection{Materials and Methods for Hydrothermal Degradation of Biomass}

For the investigation of the hydrothermal degradation of real biomass, experiments were performed with grass suspensions. The typical grass sample was dried at $313 \mathrm{~K}$ until complete dryness, milled with a ball mill, and sieved to a particle size of $<0.1 \mathrm{~mm}$. This grass powder was used as a suspension of $1 \% w / w$ in water (stirred overnight for soaking). Experiments were done as not-catalyzed as well as homogeneously catalyzed reactions-for the catalyzed reactions, $5 \% w / w$ of $\mathrm{K}_{2} \mathrm{CO}_{3}$ (according to the whole suspension mass) was added to the suspension.

The continuous reactor (cf. Figure 2, left) used for the biomass degradation experiments is a coiled tube (CTR: $4 \mathrm{~m}$ length, $7 \mathrm{~mm}$ inner diameter) with a preheater and decompression vent. Advantages of this kind of reactor in contrast to a batch autoclave are its fast heating by using a heating band, plug flow, and fast cooling behavior. Residence time in the reactor is controlled by velocity regulation of the pump. The grass suspension in the reactor was processed at temperatures of 553, 573, and $593 \mathrm{~K}$ with autogenous pressure at different residence times.
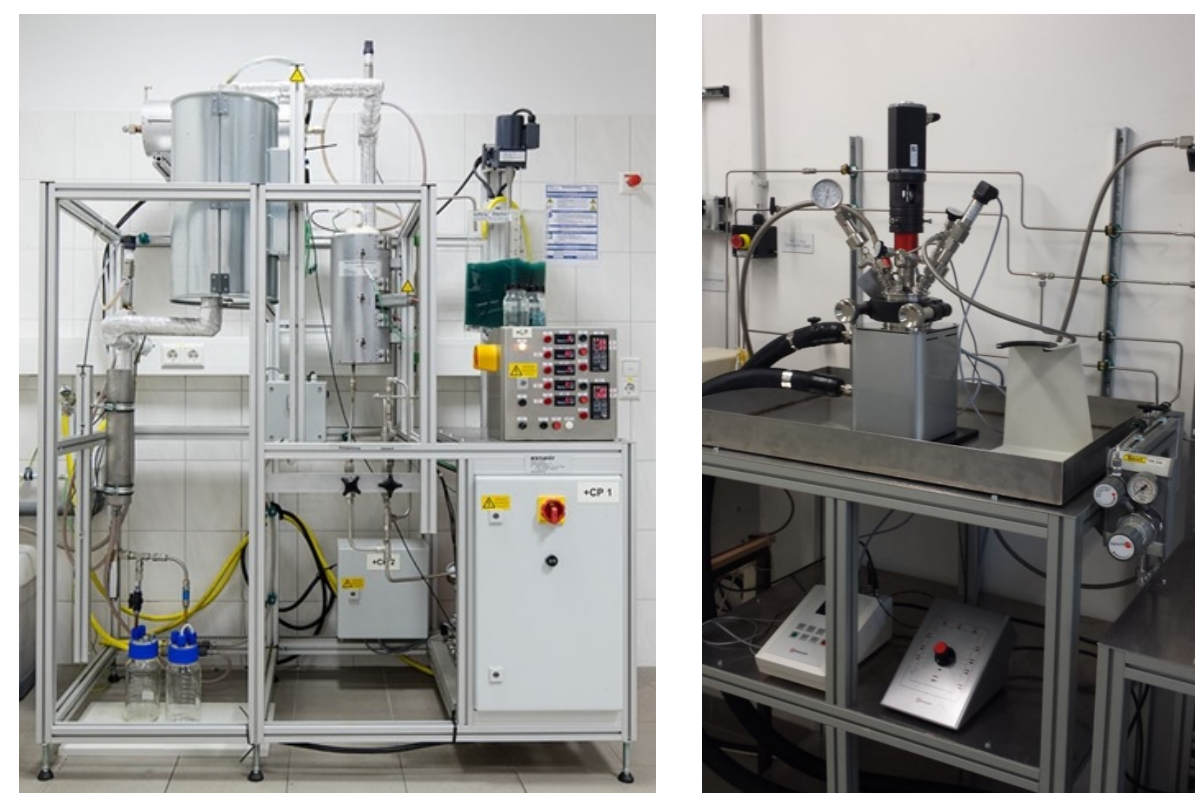

Figure 2. Photographs of the continuous reactor (left, cf. Section 2.1) and the batch reactor (right, cf. Section 2.3, part 1). 


\subsection{Preparation and Characterization of Solid Catalysts}

As solid catalysts $\mathrm{Al}_{2} \mathrm{O}_{3}, \mathrm{ZrO}_{2}$ and activated carbon (AC) based supports with $\mathrm{Pt}, \mathrm{Ru}, \mathrm{Pd}$ as well as $\mathrm{Fe}, \mathrm{Co}, \mathrm{Ni}$ as metal components were chosen. Prior to the catalytic experiments, all catalysts were reduced at $623 \mathrm{~K}$ under a flow of $\mathrm{H}_{2}\left(2.0 \mathrm{~cm}^{3} \mathrm{~min}^{-1}\right)$ in $\mathrm{N}_{2}\left(8.0 \mathrm{~cm}^{3} \mathrm{~min}^{-1}\right)$ for $4 \mathrm{~h}$.

Characterization of the catalysts followed the instructions given by Al-Naji et al., 2020 [32].

The catalyst stability was investigated during a hydrogenation of LA with FA ( $\mathrm{x}_{\text {cat. }}=0.24 \% w / w$ in reactant solution, $\mathrm{T}=493 \mathrm{~K}, \mathrm{c}_{\mathrm{LA}}=22.06 \mathrm{~g} \mathrm{~L}^{-1}, \mathrm{c}_{\mathrm{FA}}=27.16 \mathrm{~g} \mathrm{~L}^{-1}, \mathrm{c}_{\mathrm{V}}=4.56 \mathrm{~g} \mathrm{~L}^{-1}, n=700 \mathrm{~min}^{-1}$ stirring speed, and autogenous pressure).

\subsection{Materials and Methods for Hydrogenation of Model Substances}

The investigations of the hydrogenation of model substances and real biomass degradation products were subdivided into different parts.

Part 1-The experiments of part 1 were carried out in a $500 \mathrm{~mL}$ stainless steel batch reactor (Berghof Products + Instruments GmbH, Eningen, Germany; reactor type BR-500, max. pressure $20 \mathrm{MPa}$ at max. temperature $573 \mathrm{~K}$, cf. Figure 2, right with adjustable reactor head and fixed reactor vessel (tightly closed with a PTFE seal ring) within a heating mantle box. On top of the reactor head, the stirrer motor was mounted and connected to the stirrer axis via magnet coupling. The stirrer itself is characterized as straight blade gas-entrainment stirrer with a fixing ring at the bottom of the inner reactor vessel. The heating mantle box was connected to an external thermostat (Julabo GmbH, Seelbach, Germany; thermostat type SL-6) and provided controlled reactor heating via a suitable thermo oil. If needed, fast cooling was provided by an independent cryostat (Julabo $\mathrm{GmbH}$, Seelbach, Germany; cryostat type F $25 \mathrm{MA}$ ). The pressure within the reactor was controlled and adjusted via a pressure valve (Spectrolab, Division of KPG Design Group GmbH, Täferrot, Germany; valve type LM 516 ) connected to the gas $\left(\mathrm{N}_{2}\right.$, $\mathrm{H}_{2}$ ) supply tubing.

Experimental studies with a model mixture were done in the presence of a commercially available $\mathrm{Ru} / \mathrm{AC}$ catalyst and gaseous hydrogen. Based on literature data and preliminary experimental tests, the following process conditions were chosen for further investigations: $\mathrm{T}=433-473 \mathrm{~K}, p=3.4 \mathrm{MPa}$ with added gaseous hydrogen, $\mathrm{Ru} / \mathrm{AC}$ catalyst ( $\%$ w/w Ru on $\mathrm{AC}$ powder), $\mathrm{x}_{\mathrm{cat}} .=1 \% w / w$ in reactant solution, $\mathrm{c}_{\mathrm{FF}}=5 \mathrm{~g} \mathrm{~L}^{-1} ; \mathrm{c}_{\mathrm{LA}}=20 \mathrm{~g} \mathrm{~L}^{-1} ; \mathrm{c}_{\mathrm{V}}=7.5 \mathrm{~g} \mathrm{~L}^{-1} ; \mathrm{c}_{\mathrm{FA}}=25 \mathrm{~g} \mathrm{~L}^{-1}$. Main target products were GVL, MMP, and 2-methyltetrahydrofuran (MTHF). Samples from the experiments conducted were taken in certain intervals.

Part 2-The catalytic experiments were carried out in a $300 \mathrm{~mL}$ stainless steel batch reactor (Parr Instruments Company, Moline, IL, USA, reactor type 4560) [32]. The reactor was equipped with a head stirrer and temperature, pressure and stirring speed were monitored externally. To investigate step 2 in the absence of gaseous hydrogen, a two component aqueous mixture containing LA and FA ( $c_{\mathrm{LA}}=22.06 \mathrm{~g} \mathrm{~L}^{-1}, \mathrm{c}_{\mathrm{FA}}=27.16 \mathrm{~g} \mathrm{~L}^{-1}$ ) was converted under the following conditions: $0.3 \mathrm{~g}$ of the reduced catalyst and $125 \mathrm{~mL}$ of the mentioned aqueous solution of LA and FA were processed after purging the air out of the reactor system by nitrogen. The experiments were then carried out at $493 \mathrm{~K}$ with a stirring speed of $700 \mathrm{~min}^{-1}$ under autogenous pressure. Liquid samples were taken in certain intervals (starting time $=0=$ time, when the desired temperature was reached, typically within $30 \mathrm{~min}$ ) and centrifuged to separate the solid from the liquid sample.

Part 3-In order to mimic the complexity of real lignocellulosic biomass-derived hydrolysates, a model mixture containing LA, V, and FA has been used in further experiments in the Parr mini-reactor (see above; $\mathrm{x}_{\text {cat. }}=0.24 \% w / w$ in reactant solution, $\mathrm{T}=493 \mathrm{~K}, \mathrm{c}_{\mathrm{LA}}=22.06 \mathrm{~g} \mathrm{~L}^{-1}, \mathrm{c}_{\mathrm{FA}}=27.16 \mathrm{~g} \mathrm{~L}^{-1}, \mathrm{c}_{\mathrm{V}}=$ $4.56 \mathrm{~g} \mathrm{~L}^{-1}, n=700 \mathrm{~min}^{-1}$ stirring speed, autogenous pressure).

\subsection{Development of the Two Stage Hydrothermal Laboratory Plant}

The developed reactor concept for the hydrogenation of biomass with internally produced hydrogen donor substances in continuous mode is divided into two stages according to the intended 
way of process and—as the development was a special part of the project—described in Section 3.4 in detail.

\subsection{Materials and Methods for the Investigations on the Laboratory Plant}

Part 1-The investigations for the first stage were carried out in the developed laboratory plant, outlined in Section 3.4. For the investigation of the hydrothermal degradation of real biomass according to the experiments from Section 3.1, experiments were performed with grass suspensions, which were prepared in the same way as described in Section 2.1. Experiments were done as not-catalyzed as well as homogeneously catalyzed reactions - for the catalyzed reactions $1 \% w / w$ of $\mathrm{K}_{2} \mathrm{CO}_{3}$ (according to the whole suspension mass) was added to the suspension.

Part 2-The experiments for the second stage were done with an aqueous model mixture containing $\mathrm{LA}, \mathrm{FA}$ and $\mathrm{V}\left(\mathrm{c}_{\mathrm{LA}}=21.5 \mathrm{~g} \mathrm{~L}^{-1}, \mathrm{c}_{\mathrm{FA}}=25.6 \mathrm{~g} \mathrm{~L}^{-1}, \mathrm{c}_{\mathrm{V}}=5 \mathrm{~g} \mathrm{~L}^{-1}\right)$. The solid catalyst $1 \mathrm{Pt} / 60 \mathrm{Boehmite}-40 \mathrm{SiO}_{2}$ was activated with hydrogen at $473 \mathrm{~K}$ before starting the experiment, afterwards the reactor was flushed with nitrogen. Because of the long reaction time, the experiment was carried out in batch mode at $493 \mathrm{~K}$ for $6 \mathrm{~h}$ with a stirring speed of $700 \mathrm{~min}^{-1}$.

Part 3-The real product mixture from the first stage degradation of grass suspension (cf. part 1) was converted in the second stage of the developed laboratory plant with the above mentioned solid catalyst and $10 \mathrm{MPa}$ hydrogen for $8 \mathrm{~h}$ and at $493 \mathrm{~K}$ in a batch mode with a stirring speed of $100 \mathrm{~min}^{-1}$.

\subsection{Analysis Methods}

The product samples of the hydrothermal degradation steps (Section 2.1) were analyzed by HS-GC-FID (organic acids, 5-methylfurfural (MF)) [33] and HPLC-DAD/RID (LA [34] and 5-hydroxymethylfurfural (HMF) resp. furfural (FF) [35]). Samples of the Section 2.3, part 1, were analyzed by HPLC-RI (column: Eurokat $\mathrm{Pb}$, particle size $10 \mu \mathrm{m}, 30 \times 8 \mathrm{~mm}$ pre-column, $300 \times 8 \mathrm{~mm}$ separating column; $\mathrm{T}_{\text {oven }}=338 \mathrm{~K}$; eluent: degassed, deionized $\mathrm{H}_{2} \mathrm{O}$; eluent flow: $0.7 \mathrm{~mL} \mathrm{~min}^{-1}$ ).

During the experiments, described in the Sections 2.2 and 2.3, parts 2 and 3, the conversion of LA, FA, and $\mathrm{V}\left(\mathrm{X}_{\mathrm{LA}}, \mathrm{X}_{\mathrm{FA}}\right.$, and $\left.\mathrm{X}_{\mathrm{V}}\right)$ as well as the yields of GVL, pentanoic acid (PA), and 2-methoxy-4-methylphenol (MMP; $\mathrm{Y}_{\mathrm{GVL}}, \mathrm{Y}_{\mathrm{PA}}$, and $\mathrm{Y}_{\mathrm{MMP}}$ ) were calculated by signal area integration, as outlined in [32].

For analysis of phenolic compounds and other emerging interesting components by using GC-MS (cf. Sections 3.1 and 3.5) the samples were treated as follows: $700 \mu \mathrm{L}$ of the product solution were extracted with $400 \mu \mathrm{L}$ toluene by intensive mixing. After phase separation (after $20 \mathrm{~min}$ ) the toluene phase of the sample was analyzed by GC-MS. A ZB-5HT Inferno column $(30 \mathrm{~m} \times 0.25 \mathrm{~mm} \times 0.25 \mu \mathrm{m}$; Phenomenex) was used. The injection temperature was $523 \mathrm{~K}$ (split ratio 10:1, injection volume $1 \mu \mathrm{L}$ ). The constant gas flow was $1.2 \mathrm{~mL} \mathrm{~min}^{-1}$. The column temperature program was set to $323 \mathrm{~K} \rightarrow\left(5 \mathrm{~K} \mathrm{~min}^{-1}\right) \rightarrow 498 \mathrm{~K} \rightarrow\left(30 \mathrm{~K} \mathrm{~min}^{-1}\right) \rightarrow 573 \mathrm{~K}$ (for $5 \mathrm{~min}$ ). All masses from 50 to $450 \mathrm{u}$ were registered. The device is calibrated by manufacturing a mixed calibration solution (with 4-tertbutylphenol as ISTD) of the components in the following ranges of concentration: phenol (2.701-270.1 mg L-1), o-cresol (2.610-261.0 mg L-1), sum of m-/p-cresol (4.574-457.4 mg L-1), guaiacol (2.777-277.7 mg L $\left.\mathrm{mg}^{-1}\right)$, syringol (2.309-230.9 $\left.\mathrm{mg} \mathrm{L}^{-1}\right)$, eugenol $\left(2.597-259.7 \mathrm{mg} \mathrm{L}^{-1}\right), \mathrm{V}$ (2.645-264.5 $\left.\mathrm{mg} \mathrm{L}^{-1}\right)$ and syringaldehyd (1.297-129.7 $\left.\mathrm{mg} \mathrm{L}^{-1}\right)$. Other peaks were only qualitatively identified (by comparison with the NIST-database and in the case of GVL by comparison with the pure substance).

\section{Results of the Investigation to the Key Questions}

\subsection{Hydrothermal Degradation of Biomass}

Based on extensive laboratory tests for the hydrothermal conversion of model substances such as glucose, cellulose, xylan, pure lignin, and $\mathrm{V}$ the hydrothermal degradation of a suspension of grass as real biomass in water was investigated (cf. Section 2.1). 
The analysis results of the experiment with and without homogenous catalyst at different reaction temperatures are shown in Figures 3 and 4. The concentrations of FA and acetic acid (AA) without catalyst were only slightly influenced by temperature and residence time (34-140 mg L $^{-1} \mathrm{FA}$, 250-360 mg L ${ }^{-1} \mathrm{AA}$ ). By using the catalyst $\mathrm{K}_{2} \mathrm{CO}_{3}$, the FA concentrations increased with increasing temperature and residence time (Figure 3). However, FA concentrations in the range of $300-536 \mathrm{mg} \mathrm{L}^{-1}$ were reached. The effect of the presence of the catalyst on the yields of AA is lower as observed during formation of FA—only concentrations in a range of $250-450 \mathrm{mg} \mathrm{L}^{-1}$ were reached.
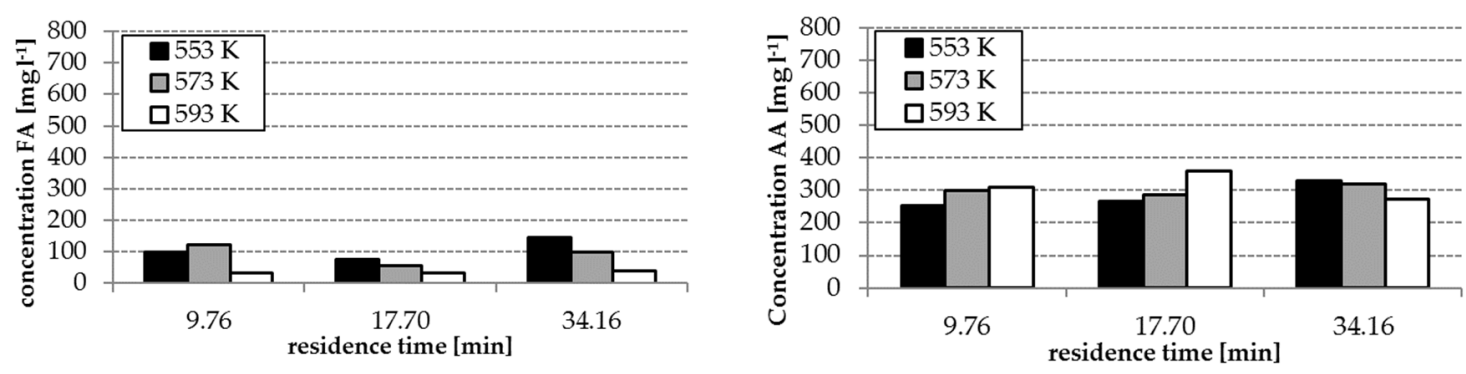

Figure 3. Concentrations of formic acid (FA) and acetic acid (AA) after hydrothermal treatment of grass suspensions without a catalyst (CTR, $1 \% w / w$ grass powder suspended in water; residence time: 9.76-34.16 $\mathrm{min}$, reaction temperature: 553-593 K).
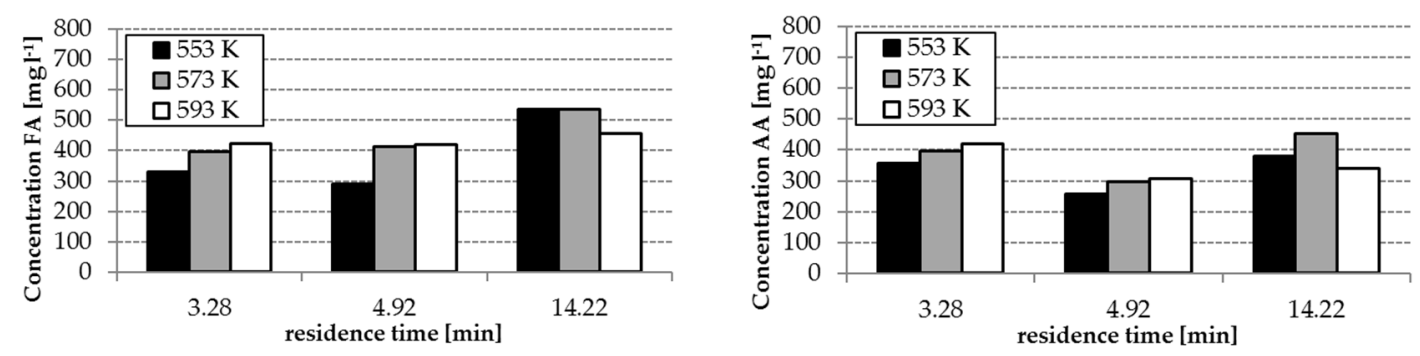

Figure 4. Concentrations of FA and AA after hydrothermal treatment of grass suspensions with catalyst (CTR, $1 \% w / w$ grass powder and 5\% w/w K2CO3 suspended in water; residence time: 3.28-14.22 min, reaction temperature: $553-593 \mathrm{~K})$.

Alternatively, the formation of furan derivatives was considerably influenced by the catalyst. In the absence of the catalyst, furan derivatives were measured (HMF: $2.67-8.23 \mathrm{mg} \mathrm{L}^{-1}$, MF: $0.48-1.35 \mathrm{mg} \mathrm{L}^{-1}$, FF: $4.49-13.8 \mathrm{mg} \mathrm{L}^{-1}$ ); by using the catalyst, no furan derivatives were detected. The dosage of $\mathrm{K}_{2} \mathrm{CO}_{3}$ causes a significant increase of the potassium $(\mathrm{K})$ content of the suspension and an increase of the $\mathrm{pH}$ value $\left(3 \mathrm{mg} \mathrm{L}^{-1} \mathrm{~K}\right.$ and a $\mathrm{pH}$ of 5 in a suspension without catalyst versus $288 \mathrm{mg} \mathrm{L}^{-1} \mathrm{~K}$ and a $\mathrm{pH}$ of $10.6-11.1$ in a suspension with $5 \% w / w \mathrm{~K}_{2} \mathrm{CO}_{3}$ ). According to [36,37], the alkaline $\mathrm{pH}$ is responsible for the increased contents of FA and AA because an initial alkaline $\mathrm{pH}$ value of the hydrothermal conversion of cellulose leads to the formation of mainly carboxylic acids and not any furan derivatives.

As phenolic compounds up to $5.6 \mathrm{mg} \mathrm{L}^{-1}$ phenol, $20.7 \mathrm{mg} \mathrm{L}^{-1}$ guaiacol, and $5.2 \mathrm{mg} \mathrm{L}^{-1}$ of $\mathrm{V}$ were measured under these conditions, absence of the catalyst had no influence on the formation of phenolic compounds (9.8 $\mathrm{mg} \mathrm{L}^{-1}$ phenol, $7.3 \mathrm{mg} \mathrm{L}^{-1}$ guaiacol, and $7.3 \mathrm{mg} \mathrm{L}^{-1} \mathrm{~V}$ ).

The compound LA was only formed in the absence of the catalyst with concentrations in a range of 7-15 $\mathrm{mg} \mathrm{L}^{-1}$. By using a catalyst, the formation of LA did not take place.

Reaction temperature, residence time and the absence/presence of $\mathrm{K}_{2} \mathrm{CO}_{3}$ have an influence on the composition of the hydrothermal degradation product solution. The highest concentrations of FA and AA as possible hydrogen donors for the step 2 of the process were received with temperatures of 553 and $573 \mathrm{~K}$, a residence time of $14.22 \mathrm{~min}$ and the application of $\mathrm{K}_{2} \mathrm{CO}_{3}$. (cf. Figure 4). With these conditions, the formation of HMF, which tends to polymerization, can be avoided. This is advantageous for the protection of the solid catalyst in step 2 of the whole process (cf. Section 3.4) 


\subsection{Upgrading of Degradation Products by Hydrogenation in the Presence of Solid Catalysts}

Within degradation during step 1, hydrogen acceptors (e.g., FF, HMF, LA, and V) and hydrogen donors (e.g., FA) are formed. In step 2, as explained in Section 1, a hydrogenation with internally produced hydrogen is very much favored above a process by utilization of molecular hydrogen. Possible reaction pathways can be described as

Step 1:

$$
\begin{aligned}
& \text { glucose } \leftrightarrow \text { fructose } \rightarrow \mathrm{HMF} \rightarrow \mathrm{LA}+\mathrm{FA} \\
& \text { xylose } \rightarrow \text { FF. }
\end{aligned}
$$

Step 2:

$\mathrm{FA} \rightarrow \mathrm{H}_{2}+\mathrm{CO}_{2}$

LA $\rightarrow$ hydroxypentanoic acid $\rightarrow$ GVL

$\mathrm{V} \rightarrow$ vanillin alcohol (+FA and metal catalyst) $\rightarrow$ MMP.

For upgrading of the product solution derived from step 1 to GVL and MMP as main products, a catalyst is needed and must fulfill special requirements. Under hydrothermal conditions, a lot of catalysts are not stable because of the increased pressure, the high temperature, and, as a consequence, the properties of water. That is why adapted catalysts especially with high stability under hydrothermal conditions within step 2 had to be an outcome of the research. For first tests of the stability of these catalysts, it is still advantageous to work in a hydrogen atmosphere. For further investigations, tests with multicomponent model mixtures of FA as hydrogen donor and different hydrogen acceptors, which are characteristic for the product solution of step 1, have taken place.

For further processing the product from hydrothermal biomass degradation (step 1), bifunctional, mono, and bimetallic catalysts with enhanced hydrothermal stability were focused on three systems, i.e., $\mathrm{Al}_{2} \mathrm{O}_{3}, \mathrm{ZrO}_{2}$, and activated carbon (AC)-based supports with $\mathrm{Pt}, \mathrm{Ru}$, and $\mathrm{Pd}$ and $\mathrm{Fe}, \mathrm{Co}$, and $\mathrm{Ni}$ as metal components. The supports were selected based on previous preliminary tests regarding stability with LA and FA (from cellulose/hemicellulose) and V (from lignin) as common products of hydrothermal biomass degradation, which represent a hydrogen accepting and a hydrogen delivering substance.

Gamma- $\mathrm{Al}_{2} \mathrm{O}_{3}\left(\gamma-\mathrm{Al}_{2} \mathrm{O}_{3}\right)$ based catalysts show a low hydrothermal stability with a rapid phase transformation to boehmite under the conditions applied in the aqueous phase hydrogenation, associated with a decrease in specific BET surface area $\left(\mathrm{A}_{\mathrm{BET}}\right)$ from $280 \mathrm{~m}^{2} \mathrm{~g}^{-1}$ to $60 \mathrm{~m}^{2} \mathrm{~g}^{-1}$ after $24 \mathrm{~h}$. Nevertheless, the supported $\gamma-\mathrm{Al}_{2} \mathrm{O}_{3}$ catalysts remain active over $24 \mathrm{~h}$. Interestingly, boehmite-supported catalysts with different mass fractions of $\mathrm{SiO}_{2}$ provide an alternative with significantly higher stability. Also, stabilization of $\gamma-\mathrm{Al}_{2} \mathrm{O}_{3}$ by silylation results in a catalyst with a less pronounced degree of phase transformation and decrease in $\mathrm{A}_{\mathrm{BET}}$ from $265 \mathrm{~m}^{2} \mathrm{~g}^{-1}$ to $120 \mathrm{~m}^{2} \mathrm{~g}^{-1}$.

Catalysts based on commercial $\mathrm{ZrO}_{2}$ as support show reasonable stability, but relatively low activity mainly due to comparably low specific surface area $\mathrm{A}_{\mathrm{BET}} 65 \mathrm{~m}^{2} \mathrm{~g}^{-1}$ and acid site density (ASD) $9 \mu \mathrm{mol} \mathrm{g}{ }^{-1}$. Hence, different mesoporous $\mathrm{ZrO}_{2}$ based catalysts with tailor made $\mathrm{A}_{\mathrm{BET}}\left(140-220 \mathrm{~m}^{2} \mathrm{~g}^{-1}\right)$ and ASD (76-136 $\left.\mu \mathrm{mol} \mathrm{g}{ }^{-1}\right)$ were investigated. The mesoporous $\mathrm{ZrO}_{2}$ with highest $\mathrm{A}_{\mathrm{BET}}$ and ASD were the most active and stable (cf. Section 2.4).

Although AC is often successfully used for hydrothermal processes $[12,13,16]$, our experiments show a different picture- $\mathrm{AC}$ was found to be an unstable catalyst support under the conditions applied accompanied by a significant decrease in $\mathrm{A}_{\mathrm{BET}}\left(1200 \mathrm{~m}^{2} \mathrm{~g}^{-1}\right.$ to $110 \mathrm{~m}^{2} \mathrm{~g}^{-1}$, after $\left.24 \mathrm{~h}\right)$ as well as partial phase transformation. However, hydrothermal reactions often take place in much less than $24 \mathrm{~h}$, so that the use of a carbon-based carrier is not generally excluded. Furthermore, AC can be stabilized by deposition precipitation of $\mathrm{Nb}$ showing only a slight decrease in $\mathrm{A}_{\mathrm{BET}}\left(1100 \mathrm{~m}^{2} \mathrm{~g}^{-1}\right.$ to $\left.980 \mathrm{~m}^{2} \mathrm{~g}^{-1}\right)$ after $24 \mathrm{~h}$ of catalytic experiment. 


\subsection{Hydrogenation of Model Substances}

For the investigation of the hydrogenation as step 2, experiments with different aqueous model mixtures in order to mimic the product range of step 1 have been conducted.

Part 1-Experimental studies with a model mixture containing FF, LA, FA and V were carried out in presence of a commercially available $\mathrm{Ru} / \mathrm{AC}$ catalyst and gaseous hydrogen (cf. Section 2.3, part 1). The choice for Ru was made due to its generally lower costs than Pt and the reports on other comparable chemical reactions. Thus, gaseous hydrogen was initially added (instead of any inert gas) to the reaction mixture, to make sure that hydrogenation toward the desired products will result in measurable yields and allow conclusions on the influence of process parameters.

The investigation of the temperature influence elucidated that quantitative conversion of LA to GVL $(98.7 \%$ and towards $100 \%)$ were obtained at $453 \mathrm{~K}$ and $473 \mathrm{~K}$ after $190 \mathrm{~min}\left(\mathrm{c}_{\mathrm{GVL}, 190 \mathrm{~min}}=17.0 \mathrm{~g} \mathrm{~L}^{-1}\right.$ and $18.3 \mathrm{~g} \mathrm{~L}^{-1}$ ), whereas MTHF molar yields were lower at $453 \mathrm{~K}$ and lowest at $473 \mathrm{~K}$, compared to $433 \mathrm{~K}(38 \%$, based on reactant FF), cf. Figure 5.

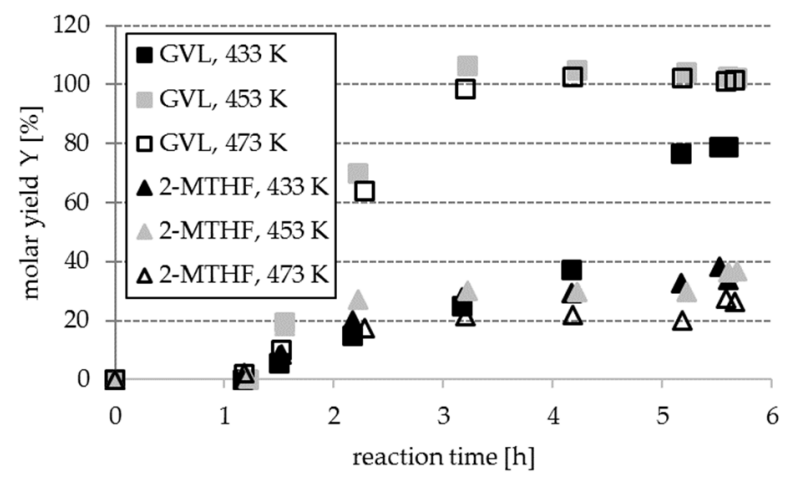

Figure 5. Molar yields of $\gamma$-valerolactone (GVL) and 2-methyltetrahydrofuran (MTHF) as a function of reaction time during the reaction of levulinic acid (LA), vanillin (V), FA, and furfural (FF) in presence of an $\mathrm{Ru} / \mathrm{AC}$ catalyst and hydrogen $\left(\mathrm{x}_{\text {cat. }}=1 \% \mathrm{w} / \mathrm{w}\right.$ in reactant solution, $\mathrm{T}=433-473 \mathrm{~K}, \mathrm{c}_{\mathrm{FF}}=5 \mathrm{~g} \mathrm{~L}^{-1}, \mathrm{c}_{\mathrm{LA}}$ $\left.=20 \mathrm{~g} \mathrm{~L}^{-1}, \mathrm{c}_{\mathrm{FA}}=25 \mathrm{~g} \mathrm{~L}^{-1}, \mathrm{c}_{\mathrm{V}}=7.5 \mathrm{~g} \mathrm{~L}^{-1}, p=3.4 \mathrm{MPa}\right)$.

Part 2-Further there were experiments in the absence of gaseous hydrogen were carried out (cf. Section 2.3, part 2). In contrast to the aqueous phase hydrogenation with externally supplied hydrogen for which Ru is the most active metal [38,39], Pt was found to be the most active metal for the aqueous phase hydrogenation of the model mixture. In comparison to the monometallic supported $\mathrm{Pt}$, bimetallic catalysts showed an up to $20 \%$ higher GVL yield after $24 \mathrm{~h}$ reaction time. The highest GVL yield of $90 \%$ is observed in presence of $\mathrm{Pt}-\mathrm{Co} / \gamma-\mathrm{Al}_{2} \mathrm{O}_{3}$. Non-noble metal catalysts, i.e., Fe and $\mathrm{Co}$, alone do not show any significant hydrogenation activity. In presence of the stable 3Pt-9Co on silylated and calcined $(1073 \mathrm{~K}) \gamma-\mathrm{Al}_{2} \mathrm{O}_{3}$, an only slightly lower GVL yield compared to $3 \mathrm{Pt}-9 \mathrm{Co} / \gamma-\mathrm{Al}_{2} \mathrm{O}_{3}$ (without silylation and calcination) is achieved, resulting in $60 \%$ (without silylation and calcination) and $47 \%$ (with silylation and calcination) after $6 \mathrm{~h}$, respectively. In the presence of Pt catalysts supported on mesoporous $\mathrm{ZrO}_{2}$ the GVL yield increased with increasing $\mathrm{A}_{\mathrm{BET}}$ as well as ASD and amounts to $78 \%$ after $24 \mathrm{~h}$ for the catalyst with the highest $\mathrm{A}_{\mathrm{BET}}$ and ASD $\left(1.6 \mathrm{Pt} / \mathrm{ZrO}_{2}\right)$, which was also found to be hydrothermally stable after two catalytic experiments (cf. Section 2.3). At higher reaction temperatures up to $533 \mathrm{~K}$, the hydrogenation in the presence of $1.6 \mathrm{Pt} / \mathrm{ZrO}_{2}$ also results in the formation of $\mathrm{PA}$ as a product of consecutive GVL hydrogenation (see also [32]). However, PA is not found in presence of the $\mathrm{Al}_{2} \mathrm{O}_{3}$ - or AC-based catalysts at comparable reaction conditions. An overview of the results is shown in Table 1. 
Table 1. Overview of GVL yields using different catalysts (batch experiments in the Parr mini-reactor with $0.3 \mathrm{~g}$ catalyst in $125 \mathrm{~mL}$ of aqueous solution with $\mathrm{c}_{\mathrm{LA}}=22.06 \mathrm{~g} \mathrm{~L}^{-1}, \mathrm{c}_{\mathrm{FA}}=27.16 \mathrm{~g} \mathrm{~L}^{-1}, \mathrm{~T}=493 \mathrm{~K}$, $n=700 \mathrm{~min}^{-1}$ stirring speed, autogenous pressure), cf. Section 2.3, part 2.

\begin{tabular}{cc}
\hline Catalyst & GVL Yield [\%] \\
\hline Pt-Co $/ \gamma-\mathrm{Al}_{2} \mathrm{O}_{3}$ & 90 \\
$3 \mathrm{Pt}-9 \mathrm{Co} / \gamma-\mathrm{Al}_{2} \mathrm{O}_{3}$ (support silylated and calcined at $1073 \mathrm{~K}$ ) & 47 \\
$3 \mathrm{Pt}-9 \mathrm{Co} / \gamma-\mathrm{Al}_{2} \mathrm{O}_{3}$ (support without silylation and calcination) & 60 \\
$1.6 \mathrm{Pt} / \mathrm{ZrO}_{2}$ & 78 \\
\hline
\end{tabular}

In experimental tests using a HMF, LA, V, and FA mixture, a considerable amount of solid byproducts was formed leading to a fast catalyst deactivation. HMF was found to be the main source for solids formation, i.e., insoluble humins [40]. Therefore, the reaction conditions of hydrothermal degradation in step 1 were adjusted and a nearly HMF-free product solution could be achieved (cf. Section 2.1).

Part 3: In order to mimic the complexity of real lignocellulosic biomass-derived hydrolysates, a model mixture containing LA, V, and FA has been used in further experiments (cf. Section 2.3, part 3). When converting this model mixture, the GVL yield obtained is significantly lower as achieved during the conversion of LA with FA in the absence of V (cf. Figure 5). This result can be attributed to a competitive adsorption of LA and V on the catalyst surface. The reduction in GVL yield is different for various catalysts and shown in Figure 6 as an example for a Pt/AC catalyst. The hydrogenation product of $\mathrm{V}, \mathrm{MMP}$, was obtained over all investigated catalysts and with a yield of up to $60 \%$ in the presence of $\mathrm{Pt} / \mathrm{AC}$ after $6 \mathrm{~h}$ reaction time.

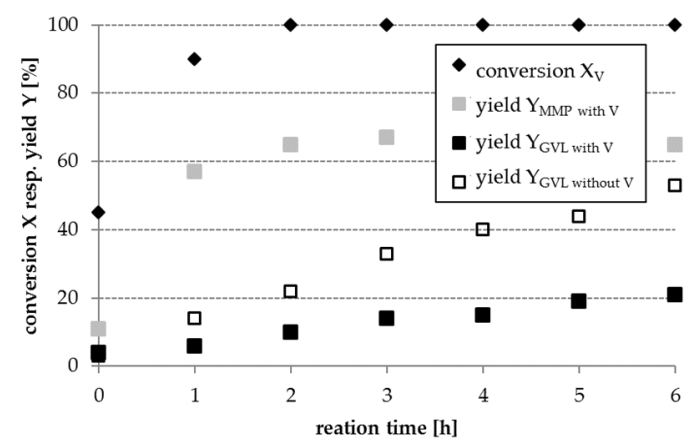

Figure 6. Conversion of $\mathrm{V}$ and yields of MMP and GVL as a function of reaction time during the hydrogenation of LA and V with FA resp. LA with FA (without V) in presence of a Pt/AC catalyst $\left(\mathrm{x}_{\text {cat. }}=0.24 \% w / w\right.$ in reactant solution, $\mathrm{T}=493 \mathrm{~K}, \mathrm{c}_{\mathrm{LA}}=22.06 \mathrm{~g} \mathrm{~L}^{-1}, \mathrm{c}_{\mathrm{FA}}=27.16 \mathrm{~g} \mathrm{~L}^{-1}, \mathrm{c}_{\mathrm{V}}=4.56 \mathrm{~g} \mathrm{~L}^{-1}$ resp. $\mathrm{c}_{\mathrm{V}}=0 \mathrm{~g} \mathrm{~L}^{-1}, n=700 \mathrm{~min}^{-1}$ stirring speed and autogenous pressure).

\subsection{Reactor Design, Reactor Modeling, and Reactor Implementation}

The developed reactor concept for the hydrogenation of biomass with internally produced hydrogen donor substances in continuous mode is divided into two stages according to the intended way of process (cf. Figure 7). The first reactor stage for hydrothermal degradation of biomass without catalyst or homogeneously catalyzed consists of a combination of a continuous tubular reactor (CTR) and stirred tank reactor (CSTR). The second reactor stage for the heterogeneously catalyzed hydrogenation of the product from the second stage is designed as a stirred tank reactor (STR) as well. 

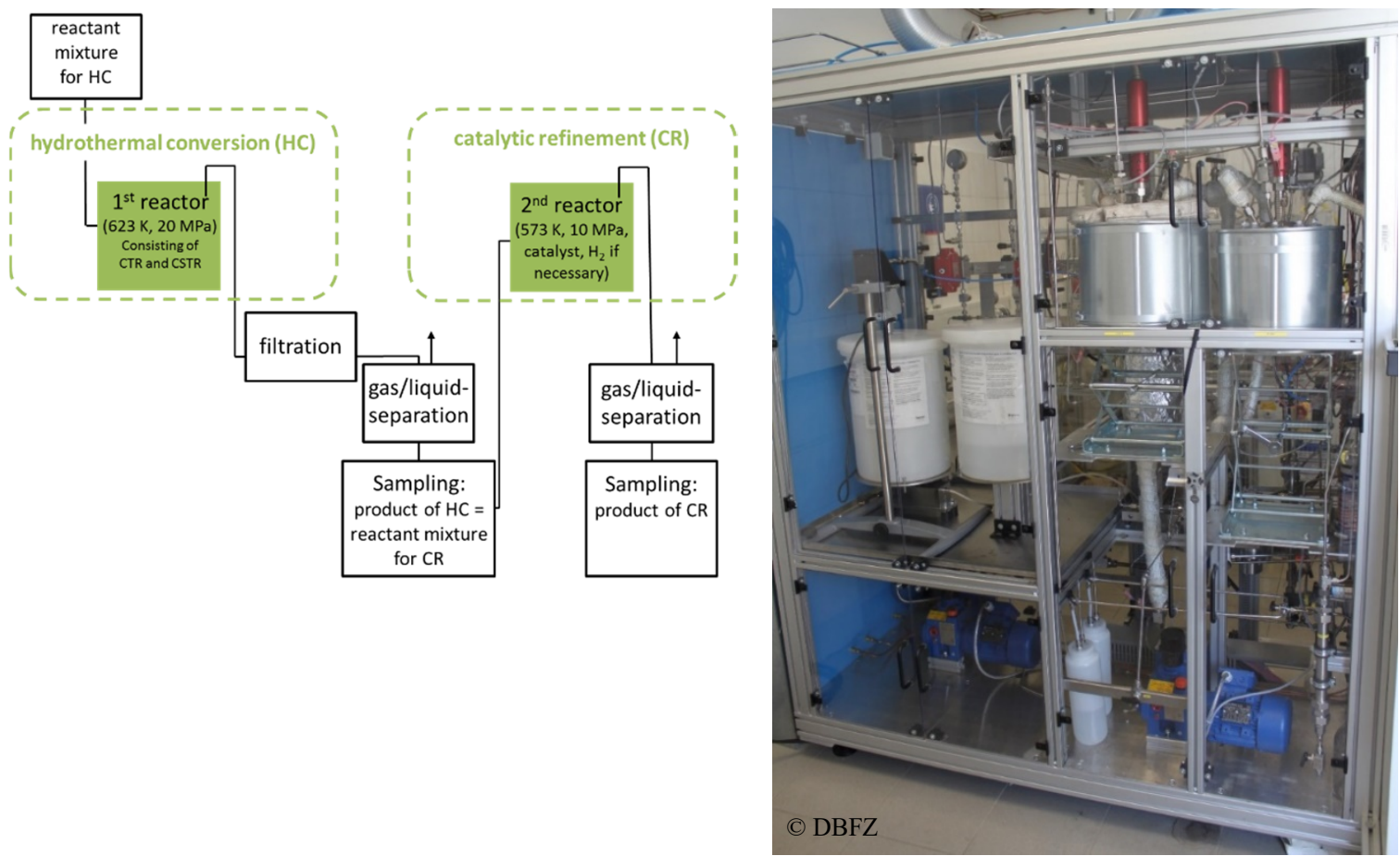

Figure 7. Schematic representation of the developed two stage reactor concept and picture of the two-stage hydrothermal laboratory plant.

The biomass is fed to the stainless steel continuous tubular reactor with a suitable pump (flow max $=3 \mathrm{~L} \mathrm{~h}^{-1}$ ) which can handle a suspension of solid biomass with defined particle size in a liquid phase. The CTR (stainless steel X6CrNiMoTi17-12-2; following the definition in DIN EN 10088-3) with a length of $5.3 \mathrm{~m}$ can be electrically heated up to $623 \mathrm{~K}$ by a heating band. Downstream of the CTR media is fed into a $200 \mathrm{~mL}$ continuous top-stirred tank reactor (CSTR, stainless steel X6CrNiMoTi17-12-2). The temperature of this reactor can be electrically adjusted up to $623 \mathrm{~K}$. The working pressure can be controlled in the range up to $20 \mathrm{MPa}$. Between the first reactor system and the reactor for the catalytic refinement (stage 2) a filtration and separation unit for removing solid by-products is installed (cf. Figure 7).

After filtration, the liquid phase is transferred to the 2nd reaction stage by a high-pressure pump $\left(\right.$ flow $_{\max }=3 \mathrm{~L} \mathrm{~h}^{-1}$ ). It enters the reactor from the top. This reactor, made from stainless steel (stainless steel X6CrNiMoTi17-12-2), possessed an usable internal volume of $500 \mathrm{~mL}$ and is equipped with a gassing stirrer. The temperature can be set up to $573 \mathrm{~K}$ by an electrical heating. A maximum working pressure of $10 \mathrm{MPa}$ can be set. Hydrogen can be automatically dosed to the reactor if necessary. To retain the solid catalyst inside the vessel, a special formed catalyst basket can be used.

\subsection{Investigation of Whole Process Chain on the Laboratory Scale}

The reactor concept was applied as a laboratory plant (cf. Section 2.5) with the aim to investigate the whole process chain up to the gas separation from the raw second stage product solution. Because of implementation problems, the experiments in the first and the second stages of the plant were not conducted successively, but independently.

Part 1-After first experiments concerning the degradation of biomass with glucose and cellulose solutions as model substances the hydrothermal degradation of grass suspensions was investigated with and without $\mathrm{K}_{2} \mathrm{CO}_{3}$. The highest yields were achieved with a dosage of $1 \% w / w \mathrm{~K}_{2} \mathrm{CO}_{3}$ at a temperature of $573 \mathrm{~K}$ after a residence time of $4.84 \mathrm{~min}$. The concentrations of organic acids amount to 400-423 mg L ${ }^{-1}$ FA, 502-528 mg L ${ }^{-1}$ AA, 254-278 mg L-1 LA and 1216-1311 $\mathrm{mg} \mathrm{L}^{-1}$ lactic acid. No furan derivatives were detected. In contrast to the experiments with $5 \% w / w \mathrm{~K}_{2} \mathrm{CO}_{3}$ in the tubular 
reactor (cf. Section 3.1), during the experiment with $1 \% w / w \mathrm{~K}_{2} \mathrm{CO}_{3}$ in the laboratory plant little amounts of LA were produced. The carbon related yields of the organic acids can be calculated to $2.4 \%$ FA, $2.3 \%$ AA, $0.6 \%$ LA, and 3.8\% lactic acid (the carbon content of the grass was analyzed to $44.65 \%$ $w / w C)$.

Part 2-1Pt/60Boehmite- $40 \mathrm{SiO}_{2}$ was used as catalyst for the heterogeneously catalyzed aqueous phase hydrogenation without gaseous hydrogen in the second stage. After $6 \mathrm{~h}$ in batch mode at $493 \mathrm{~K}$, the concentrations of the most interesting components in the product solution were as follows (the conversion rates concern to the initial concentrations):

- LA was converted up to 7.2-9.2 $\mathrm{g} \mathrm{L}^{-1}$, which corresponds to a conversion rate of $57-67 \%$;

- FA was converted up to $10.5-11.6 \mathrm{~g} \mathrm{~L}^{-1}$, which corresponds to a conversion rate of $55-59 \%$;

- V was converted up to $1.3-2.4 \mathrm{~g} \mathrm{~L}^{-1}$, which corresponds to a conversion rate of $53-74 \%$.

By GC-MS GVL, benzaldehyde, benzyl alcohol, MMP and 2-methoxyphenol could be qualitatively identified. GVL was identified by NIST database and by direct comparison with the pure substance. Benzaldehyde and benzyl alcohol are substances, which were contained in the raw as well as in the product solution.

Part 3-In contrast to the model mixture (content: LA, FA, and V), the mixture converted here contained lower concentrations of the compounds LA and FA and also other compounds. Components like AA, lactic acid (up to $1.3 \mathrm{~g} \mathrm{~L}^{-1}$ ) and little concentrations of long-chained organic acids or alcohols were identified. In this experiment, it could be shown that the concentrations of the organic acids LA and FA clearly were diminished with conversion rates of 55-61\% (LA) and 36-43\% (FA), respectively. Only MMP as one of the desired products could be analyzed qualitatively. GVL was not detectable in the product solution.

\section{Discussion of the Approach Based on the Results of the Undertaken Investigations}

In Section 1, issues to be investigated for proof of concept have been defined. The hydrothermal conversion of grass suspension as the chosen example for real biomass was processed in a tubular reactor and furthermore the identified parameters have been adapted for the conversion process in a new laboratory plant. Suitable process parameters to increase the yields of FA, LA and AA while avoiding the formation of HMF and solid by-products as product of the first step could be determined but have to get more optimized in subsequent experiments.

The stability of the catalyst has proven to be crucial for the concept. With $1 \mathrm{Pt} / 60 \mathrm{Boehmite}-40 \mathrm{SiO}_{2}$ a reasonable catalyst for the aqueous phase hydrogenation as second step was found. Further investigations for catalyst selection and optimization are necessary such as experiments with other suitable catalysts with improved stability towards the conditions in the aqueous reaction mixture from step 1 as well as higher activity and selectivity for the desired target products. In this respect both more stable supports and more stable active components should be identified. In addition, effective catalysts without noble metal are necessary before commercialization.

The scope of the work during step 2 (catalytic upgrading) was the production of value-added products without externally supplied hydrogen. As a result, the possible conversion of the chosen aqueous model mixture (V, FA, and LA) on the selected catalyst could be shown. Especially for the hydrogenation of LA to GVL very high yields up to $90 \%$ could be reached (cf. Section 3.3). In experiments with more than one substance to be hydrogenated, especially with LA and V, the yield of products for one substance is influenced by the presence of the other substance.

In the new experimental plant, the two-step-process could be implemented on the laboratory scale. Investigations for the process could be executed. The whole process on the basis of the defined representative mixture was thereby proven, and the formation of the target components GVL and MMP was qualitatively shown. Step 2, without added gaseous hydrogen, could be shown to be suitable for the conversion of model mixtures also within the new experimental plant. The new experimental plant 
could also be successfully used for step 2 with feedstock from real biomass, but so far, it has only been used with hydrogen for maintaining the process pressure.

In further research work, the processing of real biomass (especially separation of solid byproducts) within the whole chain has to be optimized. Based on this, data for engineering of the next up-scaling step has to be determined. Because further work for the investigation of the processing of real biomass within the whole chain has to be done and extrapolation of the results is limited by the laboratory plant dimension, the energy balance can only be done based on estimations. The theoretically possible efficiency of chemical conversion of carbohydrate to paraffin is $94 \%$, losses because of solids formation can be up to $12 \%$ as reported in [41] and losses during pre-heating and because of other by-products are estimated as 15\% following own experiences. Based on these estimations, an overall efficiency of $70 \%$ results.

\section{Summary}

The presented process for hydrothermal biomass liquefaction is suitable for the production of oxygen reduced substances out of predominantly wet biomass. It may be used as a basis for the development and implementation of technological approaches, which are suitable for the production of fuels and chemicals. The next necessary steps are the process optimization of the laboratory plant, scale up, and cost reduction for example by noble-metal-free catalysts. Regarding the current discussions of limited biomass potential, the actual crude oil price and the extension of electro-mobility, applications of the approach for the production of bio-based organic chemicals will potentially become more important for the future than fuel applications. Possible core-products for the two-step hydrothermal process in the production of chemicals can be for example GVL, PA, phenols, and aromatic compounds.

Author Contributions: Conceptualization, M.K. (Marco Klemm); Data curation, M.K. (Marco Klemm), M.K. (Michael Kröger), K.G., G.H., N.W. and R.G.; Funding acquisition, M.K. (Marco Klemm); Investigation, M.K. (Michael Kröger), K.G., G.H., F.L., Z.C., N.W. and M.A.-N.; Methodology, M.K. (Marco Klemm), M.K. (Michael Kröger), K.G., R.L., G.H., M.K. (Michael Krusche), F.U., N.W., M.A.-N. and R.G.; Project administration, K.G.; Resources, M.K. (Michael Krusche) and F.U.; Supervision, M.K. (Marco Klemm), R.L., S.H. and R.G.; Validation, M.K. (Marco Klemm), K.G., R.L., St.H., N.W. and R.G.; Visualization, K.G., G.H. and N.W.; Writing-original draft, M.K. (Marco Klemm), M.K. (Michael Kröger), K.G., G.H., M.K. (Michael Krusche), F.U. and N.W.; Writing一review \& editing, M.K. (Marco Klemm), K.G., R.L., G.H., S.H., M.K. (Michael Krusche), F.U., M.A.-N. and R.G. All authors have read and agreed to the published version of the manuscript.

Funding: This research was funded by German Federal Ministry of Education and Research within the project FEBio@ $\mathrm{H}_{2} \mathrm{O}$ - Liquid energy sources from the integrated hydrothermal conversion of biomass (grant number: 03EK3508).

Acknowledgments: The authors gratefully acknowledge the German Federal Ministry of Education and Research for financial support for the project FEBio@ $\mathrm{H}_{2} \mathrm{O}$-Liquid energy sources from the integrated hydrothermal conversion of biomass (grant number: 03EK3508).

Conflicts of Interest: The authors declare no conflict of interest.

\section{References}

1. Kaltschmitt, M.; Müller-Langer, F.; Neuling, U.; Remmele, E.; Thuneke, K. Produktion Und Nutzung von Pflanzenölkraftstoffen. In Energie Aus Biomasse; Springer: Berlin/Heidelberg Germany, 2016; pp. 1339-1445. [CrossRef]

2. Bereczky, Á.; Lukács, K.; Farkas, M.; Dóbé, S. Effect of $\gamma$-Valerolactone Blending on Engine Performance, Combustion Characteristics and Exhaust Emissions in a Diesel Engine. Nat. Resour. 2014, 5, 177-191.

3. Lange, J.-P.; Price, R.; Ayoub, P.M.; Louis, J.; Petrus, L.; Clarke, L.; Gosselink, H. Valeric Biofuels: A Platform of Cellulosic Transportation Fuels. Angew. Chem. Int. Ed. 2010, 49, 4479-4483. [CrossRef]

4. Brown, T.M.; Duan, P.; Savage, P.E. Hydrothermal Liquefaction and Gasification of Nannochloropsis sp. Energy Fuels 2010, 24, 3639-3646. [CrossRef]

5. Peterson, A.A.; Vogel, F.; Lachance, R.P.; Fröling, M.; Michael, J.; Antal, J.; Tester, J.W. Thermochemical biofuel production in hydrothermal media: A review of sub- and supercritical water technologies. Energy Environ. Sci. 2008, 1, 32-65. [CrossRef] 
6. Müller-Langer, F.; Klemm, M.; Schneider, J. Biofuels Production Processes and Technologies. In Biofuels Production and Processing Technology; Riazi, M.R., Chiaramont, D., Eds.; CRC Press: Boca Raton, FL, USA, 2018; pp. 153-182. ISBN 978-1-4987-7893-0.

7. Arkad, O.; Wiener, H.; Garti, N.; Sasson, Y. Catalytic transfer hydrogenation of soybean oil methyl ester using inorganic formic acid salts as donors. J. Am. Oil Chem. Soc. 1987, 64, 1529-1532. [CrossRef]

8. Brunner, H.; Kunz, M. Asymmetrische Katalysen, 31. Enantioselektive katalytische Reduktion von Dehydroaminosäuren mit Ameisensäure. Chem. Ber. 1986, 119, 2868-2873. [CrossRef]

9. Hyde, J.R.; Poliakoff, M. Supercritical hydrogenation and acid-catalysed reactions "without gases". Chem. Commun. 2004, 7, 1482-1483. [CrossRef] [PubMed]

10. Lehmann, J. Hydrierungen am Hetero-Hetero-System. Houben-Weyl Methods, 4th ed.; Reduct, I., Ed.; Georg Thieme Verlag: Stuttgart, Germany, 2014; p. IV1c.

11. Watanabe, M.; Bayer, F.; Kruse, A. Oil formation from glucose with formic acid and cobalt catalyst in hot-compressed water. Carbohydr. Res. 2006, 341, 2891-2900. [CrossRef] [PubMed]

12. Zhou, X.; Mitra, J.; Rauchfuss, T.B. Lignol Cleavage by Pd/C Under Mild Conditions and Without Hydrogen: A Role for Benzylic C-H Activation? ChemSusChem 2014, 7, 1623-1626. [CrossRef] [PubMed]

13. Gilkey, M.J.; Xu, B. Heterogeneous Catalytic Transfer Hydrogenation as an Effective Pathway in Biomass Upgrading. ACS Catal. 2016, 6, 1420-1436. [CrossRef]

14. Deng, L.; Zhao, Y.; Li, J.; Fu, Y.; Liao, B.; Guo, Q.X. Conversion of levulinic acid and formic acid into $\gamma$-valerolactone over heterogeneous catalysts. ChemSusChem 2010, 3, 1172-1175. [CrossRef] [PubMed]

15. Braden, D.J.; Henao, C.A.; Heltzel, J.; Maravelias, C.C.; Dumesic, J.A. Production of liquid hydrocarbon fuels by catalytic conversion of biomass-derived levulinic acid. Green Chem. 2011, 13, 1755. [CrossRef]

16. Jing, F.; Xiaochao, G.; Yudan, X.; Yiwen, H.; Xuebin, L. Production of $\gamma$-valerolactone from levulinic acid over a Ru/C catalyst using formic acid as the sole hydrogen source. Sci. Total Environ. 2018, 633, 426-432. [CrossRef]

17. Metzker, G.; Burtoloso, A.C. Conversion of levulinic acid into $\gamma$-valerolactone using Fe3(CO)12: Mimicking a biorefinery setting by exploiting crude liquors from biomass acid hydrolysis. Chem. Commun. (Camb.) 2015, 51, 14199-14202. [CrossRef] [PubMed]

18. Singh, A.K.; Jang, S.; Kim, J.Y.; Sharma, S.; Basavaraju, K.C.; Kim, M.-G.; Kim, K.-R.; Lee, J.S.; Lee, H.H.; Kim, D.-P. One-Pot Defunctionalization of Lignin-Derived Compounds by Dual-Functional Pd50Ag50/Fe3O4/N-rGO Catalyst. ACS Catal. 2015, 5, 6964-6972. [CrossRef]

19. Pileidis, F.D.; Titirici, M.M. Levulinic Acid Biorefineries: New Challenges for Efficient Utilization of Biomass. ChemSusChem 2016, 9, 562. [CrossRef]

20. Fagan, P.J.; Korovessi, E.; Manzer, L.E.; Mehta, R.; Thomas, S.M. Herstellung Von Lävulinsäureestern Und Ameisensäureestern Aus Biomasse Und Olefinen. DE60314382T2, 14 February 2008.

21. Kabyemela, B.M.; Takigawa, M.; Adschiri, T.; Malaluan, R.M.; Arai, K. Mechanism and Kinetics of Cellobiose Decomposition in Sub- and Supercritical Water. Ind. Eng. Chem. Res. 1998, 37, 357-361. [CrossRef]

22. Knežević, D.; van Swaaij, W.P.M.; Kersten, S.R.A. Hydrothermal Conversion of Biomass: I, Glucose Conversion in Hot Compressed Water. Ind. Eng. Chem. Res. 2009, 48, 4731-4743. [CrossRef]

23. Kruse, A.; Bernolle, P.; Dahmen, N.; Dinjus, E.; Maniam, P. Hydrothermal gasification of biomass: Consecutive reactions to long-living intermediates. Energy Environ. Sci. 2010, 3, 136-143. [CrossRef]

24. Möller, M.; Nilges, P.; Harnisch, F.; Schröder, U. Subcritical Water as Reaction Environment: Fundamentals of Hydrothermal Biomass Transformation. ChemSusChem 2011, 4, 566-579. [CrossRef]

25. Srokol, Z.; Bouche, A.-G.; van Estrik, A.; Strik, R.C.J.; Maschmeyer, T.; Peters, J.A. Hydrothermal upgrading of biomass to biofuel; studies on some monosaccharide model compounds. Carbohydr. Res. 2004, 339, 1717-1726. [CrossRef]

26. Köchermann, J.; Görsch, K.; Wirth, B.; Mühlenberg, J.; Klemm, M. Hydrothermal carbonization: Temperature influence on hydrochar and aqueous phase composition during process water recirculation. J. Environ. Chem. Eng. 2018, 6, 5481-5487. [CrossRef]

27. Bobleter, O. Hydrothermal degradation of polymers derived from plants. Prog. Polym. Sci. 1994, 19, 797-841. [CrossRef]

28. Yue, Y.; Kastner, J.R.; Mani, S. Two-Stage Hydrothermal Liquefaction of Sweet Sorghum Biomass-Part II: Production of Upgraded Biocrude Oil. Energy Fuels 2018, 32, 7620-7629. [CrossRef] 
29. Billing, J.; Hallen, R.; Schmidt, A.; Snowden-Swan, L. Hydrothermal Processing of Biomass. In DOE Bioenergy Technologies Office (BETO) 2017 Project Peer Review; Pacific Northwest National Laboratory: Richland, WA, USA, 2017.

30. Blommel, P.G.; Cortright, R.D. Production of Conventional Liquid Fuels from Sugars; Virent Energy Systems Inc.: Madison, WI, USA, 2008.

31. Virent. Fractional Multistage Hydrothermal Liquefaction of Biomass and Catalytic Conversion into Hydrocarbons; Virent Final Report for DOE Award Number 2017:DE-EE0006286; ICCT—International Council on Clean Transportation Europe: Berlin, Germany, 2017.

32. Al-Naji, M.; Popova, M.; Chen, Z.; Wilde, N.; Gläser, R. Aqueous-Phase Hydrogenation of Levulinic Acid Using Formic Acid as a Sustainable Reducing Agent Over Pt Catalysts Supported on Mesoporous Zirconia. ACS Sustain. Chem. Eng. 2020, 8, 393-402. [CrossRef]

33. Görsch, K.; Kröger, M.; Klemm, M. Hydrothermal Liquefaction of Biomass for Chemicals. In Proceedings of the 24th European Biomass Conference \& Exhibition, Amsterdam, The Netherlands, 6-9 June 2016.

34. Apelt, M. Examination of Samples of Solids (Substrates) and Digestates with HPLC for Aliphatic and Aromatic Acids, Alcohols and Aldehydes. In Collection of Methods for Biogas-Methods to Determine Parameters for Analysis Purposes and Parameters that Describe Processes in the Biogas Sector; Liebetrau, J., Pfeiffer, D., Thrän, D., Eds.; Series of the funding programme “Biomass Energy Use”; DBFZ: Leipzig, Germany, 2016; Volume 8, pp. 45-49.

35. Mühlenberg, J. Determination of Sugars and Glucose Degradation Products. In Collection of Methods for Biogas-Methods to Determine Parameters for Analysis Purposes and Parameters that Describe Processes in the Biogas Sector; Liebetrau, J., Pfeiffer, D., Thrän, D., Eds.; Series of the funding programme "Biomass Energy Use"; DBFZ: Leipzig, Germany, 2016; Volume 7, pp. 50-53.

36. Jindal, M.K.; Jha, M.K. Catalytic Hydrothermal Liquefaction of Waste Furniture Sawdust to Bio-oil. Indian Chem. Eng. 2016, 58, 157-171. [CrossRef]

37. Yin, S.; Mehrotra, A.K.; Tan, Z. Alkaline hydrothermal conversion of cellulose to bio-oil: Influence of alkalinity on reaction pathway change. Bioresour. Technol. 2011, 102, 6605-6610. [CrossRef]

38. Abdelrahman, O.A.; Luo, H.Y.; Heyden, A.; Román-Leshkov, Y.; Bond, J.Q. Toward rational design of stable, supported metal catalysts for aqueous-phase processing: Insights from the hydrogenation of levulinic acid. J. Catal. 2015, 329, 10-21. [CrossRef]

39. Tang, X.; Zeng, X.; Li, Z.; Hu, L.; Sun, Y.; Liu, S.; Lei, T.; Lin, L. Production of $\gamma$-valerolactone from lignocellulosic biomass for sustainable fuels and chemicals supply. Renew. Sustain. Energy Rev. 2014, 40, 608-620. [CrossRef]

40. Kröger, M.; Wilde, N. Konversion zu Flüssigen Energieträgern und Chemikalien. In Focus Hydrothermale Prozesse; Thrän, D., Pfeiffer, D., Klemm, M., Eds.; DBFZ: Leipzig, Germany, 2016; pp. 56-59.

41. Kröger, M.; Klemm, M. Continuous Liquefaction of Biomass Model Compounds for Chemicals and Fuels. In Proceedings of the 22th European Biomass Conference \& Exhibition, Hamburg, Germany, 23-26 June 2014; pp. 1124-1126. [CrossRef]

(C) 2020 by the authors. Licensee MDPI, Basel, Switzerland. This article is an open access article distributed under the terms and conditions of the Creative Commons Attribution (CC BY) license (http://creativecommons.org/licenses/by/4.0/). 